\title{
United States - Tax treatment for "Foreign Sales Corporations" Recourse to Arbitration by the United States under Article 22.6 of the DSU and Article 4.11 of the SCM Agreement (WT/DS108/ARB) A Comment
}

\author{
BY \\ ROBERT HOWSE \\ (University of Michigan Law School) \\ AND \\ DAMIEN J. NEVEN \\ (Graduate Institute of International Studies, Geneva)
}

Some of the legal analysis in this study derives from joint work between Robert Howse and Susan Esserman on this ruling, "Trade disputes quire fairer arbitration,” FT.com, Sep 12, 2002

\section{Introduction}

This chapter discusses the decision by the arbitrator on suspension of concessions ("retaliation") in the dispute between the US and the EU regarding the tax treatment of offshore corporate income under US legislation. By way of background, the first part of the chapter (section 2) describes the operation of the US scheme, including as revised after the first round of WTO rulings.

We observe that the arbitrators have adopted an unconventional approach with respect to the notion of countermeasures, which emphasizes the incentive to induce compliance while largely jettisoning proportionality between the countermeasure and the injury suffered by the wronged state as a meaningful normative constraint. Section 4 considers this approach from the perspective of established principles of international law and highlights a number of important shortcomings. 
Section 5 takes this approach for granted and asks whether countermeasures could actually be relied upon in order to induce compliance. We conclude with respect to export subsidies, the incentives of complainants are such that under-enforcement can often be expected.

The prospect of inducing compliance through countermeasures thus appears to be somewhat poor and at odds with established principles of international law.

\section{Facts and procedure}

This section first describes the operation of the US legislative scheme.

\subsection{The original FSC scheme}

A Foreign Sale Corporation (FSC) is a corporation established outside the United States or in some US possessions, which is involved in the sales of goods produced in the United States to foreign clients. These foreign sales corporations are typically subsidiaries of US companies and benefit from particular tax provisions under the US tax legislation. These provisions were established by the Deficit Reduction Act, adopted by Congress in 1984. In order to understand the tax benefit that flows from these provisions, some key features of the US tax system have to be described.

The US tax system is based on the residence principle, according to which the income of US residents is taxed in the US, whatever the geographical origin of the income. Hence, income generated outside the US is normally taxable in the US. Other countries apply the source principle, according to which income is taxed where it is generated. As a consequence, if income is generated in a country that applies the source principle but accrues to a beneficiary which is resident of a country applying the residence principle, income could be taxed twice. In order to avoid such double taxation, the US can either take into account the taxes paid in foreign countries by giving a tax credit ${ }^{1}$ or can simply exempt the income earned in foreign countries. ${ }^{2}$

In the case of capital income, taxes are typically paid both on the profit of a corporation but also on the income of the shareholders of the

1 This is referred to as the "capital export neutrality" principle - because capital is subject to the same tax, whether it is invested in the US or abroad.

2 This is referred to as the "capital import neutrality" principle, because capital invested in a given country is subject to the same tax, whatever the location of its owner. 
corporation when profits are distributed. Hence, the issue of double taxation arises both with respect to taxes of corporate profits (i.e. to what extent should the profit of a subsidiary or related company abroad be taxable in the US, where the parent is located) and taxes on shareholders' income (i.e. to what extent should the distribution of profits from a subsidiary or related company abroad to shareholders in the US be taxable).

Let us consider the first question, namely whether profits of a subsidiary or related company abroad should be taxable in the US. If those profits are taxed abroad and if the US adopts the approach of exempting foreign income, the definition of what can be considered as foreign income matters a great deal: under such system, US corporations will have an incentive to disguise income earned on domestic activities as foreign income (for instance, by shifting profits to foreign corporations), at least if the local tax on foreign income is very low. Hence, the US tax legislation stipulates a comprehensive set of rules to distinguish between income which is "effectively connected with a trade or business in the United States" and that which is not. Only income which is not connected with a trade or business in the United States can be exempted (will not be considered as part of the income of the US parent).

Turning to the taxes on shareholders, the US tax code stipulates that even if a foreign subsidiary or related company is not connected with a trade or business in the United States, dividends will be taxable in the US. There are also special provisions in the US tax code in order to avoid permanent deferrals of the taxes (that would arise if profits are accumulated abroad and never distributed). These provisions apply to companies that are controlled by a US parent and stipulate that US shareholders have to include their pro-rata share of profit of the foreign company in their own income. This provision effectively eliminates the opportunity of deferral for foreign companies that are controlled by shareholders resident in the US.

To sum up, the US tax legislation allows for the exemption of profits accruing to subsidiaries or related companies abroad from US corporate taxes as long as these companies are not connected with domestic activities but still impose taxes on dividends when these profits are repatriated. In addition, the payment of taxes on dividends cannot be deferred in the case of controlled companies.

The tax treatment of FSCs has four key features. First, a fraction of the income earned by an FSC is considered as "not effectively connected with a trade or business in the US" and is not subject to corporate taxes in the US. This fraction is at least $30 \%$ and is automatic. 
Second, even though FSCs are typically controlled by US parents, the rule that US shareholders (the US parent) should include their prorata share of profit in their own income does not apply to FSCs. Hence, deferral of distributed profits can take place.

Third, dividends of the FSC will be taxed in the US as long as these dividends do not exceed the exempt income, i.e. the profit that is deemed not to be connected with a trade or business in the US. For instance, if that income accounts for $30 \%$ of the FSC's total profit, as much as $30 \%$ of the profit can be distributed to shareholders without taxes on dividends.

Fourth, the transfer prices between the FSC and its US parent are subject to special rules, which allow for more flexibility than would be allowed between domestic companies. These rules effectively enable the US parents to locate a particularly high share of profits with the FSC.

\subsection{The WTO procedure}

The original FSC scheme was found to be inconsistent with the Agreement on Subsidies and Countervailing Measures (SCM), both by the panel and the Appellate Body. The panel (upheld on this point by the $\mathrm{AB}$ ), found that the FSC scheme constitutes a prohibited export subsidy under Art. 3 (1) a of the SCM agreement, essentially because in the absence of the FSC scheme, the US tax authorities would have obtained higher revenues (the tax exemptions under the FSC scheme result in the "foregoing of revenues") and because the financial benefit conferred by the FSC scheme was contingent upon export performance.

The DSB recommended that the US bring the disputed measures into conformity with the Agreement and in particular eliminate the export subsidy element that was found to exist in its taxation scheme.

The US passed a new law, the Extraterritorial Income Exclusion Act of 2000 (ETI Act). The United States and the EU disagreed as to whether this new legislation in fact eliminated the illegal export subsidy element that was impugned in the WTO proceedings.

The EU and the US had an understanding that (i) if the EU should decide to have recourse to Art. 21.5 (involving a compliance panel), it would also simultaneously request the imposition of countermeasures, using Art. 22.6, (ii) that the US would object to those measures, (iii) that the matter would be referred to arbitration and (iv) that the arbitration would be suspended until completion of a first round of 21.5 procedure (involving the adoption of a panel report and possibly an Appellate Body 
report). The parties thus committed to an arbitration procedure regarding countermeasures, but only following the 21.5 procedure.

In the 21.5 case, both the panel and the Appellate Body found that the ETI Act contained an export subsidy component and thus that the United States had failed to bring itself into compliance. The final step that remained was, then, a 22.6 arbitration on countermeasures, which is the subject of this chapter.

\section{The ruling}

We first describe the relevant legal provisions before turning to the concept of appropriate countermeasures developed by the arbitrators and evaluation of the countermeasures proposed by the EU.

\subsection{Relevant provisions}

The arbitration takes the view that the rules of the DSU with respect to the evaluation of the countermeasures apply to the SCM, except in the presence of specific rules (lex specialis).

In particular, Art. 22.7 of the DSU provides that

The arbitrator acting pursuant to paragraph 6 shall not examine the nature of the concessions or other obligations to be suspended but shall determine whether the level of such suspension is equivalent to the level of nullification or impairment

Whereas, Article 4.11 of the SCM agreement provides that

In the event a party to the dispute requests arbitration under paragraph 6 of Article 22 of the Dispute Settlement Understanding ("DSU"), the arbitrator shall determine whether the countermeasures are appropriate*

(*original footnote $\mathrm{n}^{\circ} 9$. This expression is not meant to allow countermeasures that would be disproportionate in light of the fact that the subsidies dealt with under these provisions are prohibited).

The DSU provision thus focuses on the equivalence between the level of suspension and the level of nullification or impairment whereas the SCM focuses on whether countermeasures are appropriate. Much of the arbitrators' comments are concerned with the interpretation of this last provision, given that the parties proposed rather different interpretations.

The EU proposed countermeasures for about $\$ 4$ billion, which corresponded to its own estimate of the amount of the subsidy granted by the 
FSC legislation every year. The US considered that the trade impact on the Member country concerned was the relevant benchmark to determine whether the countermeasure was "appropriate". The US further considered that the value of the subsidy could be taken as a proxy for the trade impact and hence that the proportion of the subsidy which affects the EU would be appropriate (using the share of exports to the EU in total US exports as the relevant factor). The US also encouraged the arbitrators not to use more sophisticated estimates of the trade impact (beyond the value of the subsidy).

The EU argued that the SCM agreement stipulates a particular benchmark for what is appropriate which does not relate to the trade impact but rather emphasizes the incentive to comply. The EU further considered that the value of the subsidy is conservative in terms of this benchmark.

\subsection{The concept of appropriate countermeasures}

The arbitrators effectively adopted the approach advocated by the EU.

The arbitrators first note that countermeasures are meant (just as a matter of language) to neutralize a measure but that neutralization could be understood in terms of the measure itself or in terms of its effect.

The arbitrators then take the view that countermeasures in the context of Art. 4.10 cannot be confined to redressing or neutralizing effects only. The main argument in support of their approach relates to footnote 9 of the SCM agreement, which provides some guidance of how "appropriate" should be understood. They find support for their approach in the structure of the SCM agreement, which distinguishes between "prohibited" subsidies, and subsidies that are "actionable", i.e. that may be the subject of a complaint if it can be established that they cause certain kinds of trade effects, but otherwise do not attract state responsibility.

Let us consider some of these arguments in more detail. The main argument for not confining the evaluation of "appropriate" countermeasures to an effects test (of which a trade test is just one version) rests on the interpretation of footnote 9 .

This footnote which indicates that "[appropriate] is not meant to allow countermeasures that are disproportionate in light of the fact that the subsidies dealt with under these provisions are prohibited", is a little convoluted. It reads as if it sets an upper bound on the countermeasures that can imposed (by not allowing them to be disproportionate). At the same time, it emphasizes the unlawful character of the measure at stake, which is an aggravating factor, and hence can be seen as warning against 
excessively low countermeasures or in other words as setting some lower bound on the countermeasures. The arbitrators effectively emphasize this second aspect. They observe that the measures at stake (export subsidies) are per se unlawful and hence that the imposition of such measures upsets the balance of rights and obligations under the WTO agreement, independently of their effects and in particular independently of the magnitude of their trade effects. According to the arbitrators "this emphasis on the unlawful character of the export subsidies invites ... a consideration of the impact that this unlawful character may have in itself" (Para. 5.23). "It directs us to consider the appropriateness of countermeasures under Art. 4.10 from this perspective of countering a wrongful act and taking into account its essential nature as an upsetting of the rights and obligations as between Members. This, we conclude, is the manner in which we are directed to assess the matter. We are not, by comparison, actually directed to, e.g., consider demonstrated trade effects of the measure on the complaining Member."

Having established that appropriate countermeasures in the context of Art. 4.10 do not have to be restricted to an effects test, the arbitrators consider what alternative benchmark could be used. They find inspiration in the object and purpose of the SCM agreement in relation to Art. 4.10 and those of the DSB. They observe that in this context, the DSB can only recommend that the offending member withdraw its subsidy without delay, and hence that the countermeasures, which contribute to the objective of the DSB in the case of non compliance - should have the same objective. Hence, countermeasures should be considered as an incentive mechanism and whether they are "appropriate" should be assessed in terms of whether they induce compliance, i.e. contribute to the withdrawal of the subsidy.

The consequences of this determination should not be underestimated. It implies, in particular, that what matters in evaluating the appropriateness of countermeasures is not the effect on the importing country but rather the effect on the exporting country: indeed, the amount of countermeasure that will induce compliance should at least be equal to the benefit that the exporting country obtains from the export subsidy. Hence, it is perceived benefit to the exporting country that will provide an appropriate benchmark and not the cost incurred by the importing countries. That is also to say that the arbitrators have not only argued that the trade effects on importing countries cannot provide the only benchmark for evaluating countermeasures but also proposed that the effects on the exporting countries will provide a useful benchmark. This implication however seems to have been lost on the arbitrators (see below). 
It is also worth noting that the concern about setting an upper bound on the amount of countermeasures in Art. 4.10 (such that measures should not be disproportionate) is of a second order if one takes the view that countermeasures should be used as an incentive mechanism. Indeed, only the lower bound will matter for the incentive mechanism: as long as the penalty is sufficient to induce compliance, the magnitude of the penalty will not matter - because it will not be applied (or it will be applied only during a transition period). Hence, the fact that the arbitrators emphasize the lower bound expressed in footnote 10, and tend to neglect the upper bound, is consistent with the incentive approach that they develop.

The approach which is developed by the arbitrators can also be characterized as one establishing a property rule rather than a liability rule. As emphasized by Schwartz and Sykes (2002), a property rule is a mechanism whereby a party needs to secure the permission of others before deviating from its obligations. By contrast, a liability rule is a mechanism whereby a party wishing to deviate from its obligations is only liable for the damages that the deviation causes. According to Schwartz and Sykes (2002), the main drawback of a liability rule is associated with the need to have a third party evaluate the damages. The property rule avoids this difficulty but may involve important transactions costs, associated with bargaining between the state wishing to deviate and its victims.

\subsection{Assessment of the countermeasures proposed by the EU}

In evaluating whether the amount of the export subsidy is an appropriate countermeasure, the arbitrators discuss whether it is in principle permissible, analyze the countermeasure in relation with the subsidy and discuss the extent to which the subsidy should be reduced by a factor that reflects the relative importance for the EU as an export market.

The arbitrators find that the proposed countermeasures are in principle permissible because "they are tailored to the initial wrongful act they are to counter" (Para. 6.11). The observation that countermeasures are "tailored" to the initial wrongful act arises, according to the arbitrators, from the fact that the amount of the subsidy "- the expense incurred - is the very essence of the wrongful act" (Para. 6.10).

Having established that a countermeasure which aims to "challenge the wrongful act in itself" (Para. 6.11) is in principle permissible, the arbitrators analyze the key elements of the wrongful act in order to check whether the proposed countermeasures are indeed "not disproportionate". In other words, the arbitrators attempt to derive some 
dimensions of the wrongful act along which proportionality can be assessed.

The arbitrators identify two dimensions, namely the financial contribution and the benefit to the recipients of the subsidy. With respect to the former, the arbitrators observe that the identity between the export subsidy and the countermeasure respects a form of proportionality (which goes beyond the superficial appeal that equal numbers may have). They note that the amount of the subsidy is the essential wrongful act of the US government. As the EU cannot "thwart these expenses at source," it proposes to suspend a "numerically equivalent obligation which it owes to the United States." According to the arbitrators, "it appears ... that is a proper manner from which to judge the congruence of the countermeasure to the measure at issue, i.e. to view it under its legal category: on the one hand an expense to government of a certain value constituting an upsetting of the balance of rights and obligations; and therefore, on the other hand, a congruent duty imposed by a responding government as a mirror withdrawal of an obligation" (Para. 6.19).

With respect to the benefits accruing to recipients, the arbitrators note that the EU countermeasures could be viewed "as aiming to deprive US firms of an advantage that they would otherwise receive in relation to access to the EC market" (Para. 6.21). To the extent that the countermeasures impose a cost on US firms, they could be seen as annulling or "counteracting" the benefit that they receive through the export subsidy. The arbitrators note however that computing the amount of countermeasures that would annul the benefits is hardly feasible (especially at the firm level) but that a precise equivalence is not required given that the justification for the countermeasure is to counteract the "legal breach as a wrongful act" (Para. 6.22).

The arbitrators, observing that the EU has focused on the first dimension of the subsidy but that the US has not objected to that approach, conclude that the countermeasures proposed are not disproportionate to the initial wrongful act.

The approach followed by the arbitrators in evaluating the countermeasures is surprising, to the extent that it seems to depart from the principles established earlier. In particular, the arbitrators do not attempt to apply the principle that countermeasures are meant to act as an incentive mechanism to ensure compliance. They do not even refer to this principle any longer.

One would have expected that in line with the logic of an incentive mechanism, the arbitrators would have considered the penalty that is 
required in order to make it attractive for the US to withdraw the measure. The only oblique reference to the logic of incentive can be found in the discussion of benefits to US firms (Para. 6.21) - in which the arbitrators find that a cost imposed on US firms commensurate with the benefit that they receive from the export subsidy would be appropriate. Such a cost might presumably induce US firms to ask the US government to remove the subsidy - and hence induce compliance. However, the logic of the argument is not clearly spelled out.

As indicated above, the arbitrators also discuss whether the amount of the countermeasure - evaluated as the subsidy - should be reduced to reflect the relative importance of the EU as an export market. They consider that such an approach would be inconsistent with the nature of a per se obligation - which by definition is not a quantitative matter but one of principle.

The arbitrators recognize that this approach may be problematic if there were several WTO Members demanding countermeasures - but effectively escape the problem by suggesting that they do not have to consider a set of facts that is different from the facts that they are confronted with. They note at the same time that the EU is open to the possibility of sharing the "task" (sic) of applying countermeasures with other WTO Members affected by the subsidies.

\section{Countermeasures, compliance, and proportionality}

In this section, we first recall some principles of international law with respect to the definition of countermeasures. We subsequently consider the approach of the arbitrators in light of these principles.

\subsection{Countermeasures in international law}

It is a well-established principle of international law that countermeasures in response to an internationally wrongful act must be proportional to the injury suffered by the state taking the countermeasures. This is now reflected in Article 51 of the ILC Draft Articles on State Responsibility: "Countermeasures must be commensurate with the injury suffered, taking into account the gravity of the internationally wrongful act and the rights in question." While Article 49 of the ILC Articles states the purpose of countermeasures as inducing compliance of the violating state, the effect of Article 51 is to place an essential constraint on the quantity and nature of countermeasures, such that even if a higher amount of 
countermeasures might serve the goal of inducing compliance, countermeasures are limited to what is proportional to the injury suffered. As Crawford puts it: "Proportionality is, ..., a limitation even on measures which may be justified under 49. In every case a countermeasure must be commensurate with the injury suffered, including the importance of the issue of principle involved,..." (Crawford (2002), p. 296; emphasis added). In Cannizaro's words, "the wording of Draft Article 51 clearly indicates that the ILC conceives proportionality as a factor mitigating the instrumental nature of countermeasures." (Cannizzaro (2001), p. 894).

Customary international law and general principles of international law govern the application and interpretation of WTO law, except where there is an explicit contracting out of such rules evidenced by a provision of the WTO treaties. (Korea - Government Procurement, Report of the Panel; see also EC-Hormones, Report of the Appellate Body, discussing the Precautionary Principle). Article 55 of the ILC Articles explicitly recognizes that the ILC Articles do not apply to the extent that state responsibility is governed by "special rules of international law."

As Crawford notes, "it will depend on the special rule to establish the extent to which the more general rules on State responsibility set out in the present articles are displaced by that rule." (Crawford (2002), p. 307).

There are a number of respects in which the WTO "special rules" on countermeasures obviously alter between the parties the law of countermeasures set out in the ILC Articles. First of all, breach of a primary obligation in a WTO treaty does not give rise to a right by the injured party to take countermeasures; instead, the matter must be taken to dispute settlement (DSU Article 23: US - Section 301, Report of the Panel). Then countermeasures are only available to the party or parties which have pursued dispute settlement proceedings, and only for the breach of the secondary obligation to implement a dispute settlement ruling that is binding on the parties. Such countermeasures must, furthermore, be authorized by an arbitral panel, and must not exceed the nullification and impairment of benefits resulting from the failure to implement the ruling. Thus, countermeasures may not be backdated to the time of the breach of the primary obligation; the internationally wrongful act that these countermeasures respond to is the secondary obligation to implement a binding ruling of the DSB.

Countermeasures are available also for failure to implement a nonviolation nullification and impairment ruling; this illustrates perhaps most dramatically of all the sense in which the internationally wrongful act at which countermeasures are aimed is failure to implement, because, 
of course, in non-violation nullification and impairment cases, by definition, no violation of a primary obligation has been found.

The SCM Agreement contains an even more specialized set of rules on countermeasures that apply to cases of failure to implement rulings on prohibited subsidies under the SCM Agreement. Article 4.10 provides for the authorization of "appropriate" countermeasures, where the recommendation of the DSB is not followed within the time period specified by the panel. Footnote 10 to Article 4.10 states that the wording "appropriate" is "not meant to allow countermeasures that are disproportionate in light of the fact that the subsidies dealt with under these provisions are prohibited."

In understanding this footnote, one must contrast the treatment of countermeasures with respect to prohibited subsidies under the SCM Agreement with that of another category of subsidies, labelled "actionable." The obligation of WTO Members in the case of "actionable" subsidies is one of result: in applying such subsidies, Members are required to avoid certain "adverse effects." ${ }^{3}$ Where countermeasures are authorized for failure to comply with a ruling on actionable subsidies, these countermeasures must be "commensurate with the degree and nature of the adverse effects determined to exist,...” (Article 7.8).

Footnote 9 to Article 4.10 makes it clear that in applying the notion of proportionality in the case of prohibited subsidies commensurability of countermeasures need not be measured against the existence of the adverse effects that Members are obliged to avoid in respect of actionable, as opposed to prohibited, subsidies. Nothing in the language of Footnote 9, however, evinces a clear intent to do away, in the case of prohibited subsidies, with the principle stated in ILC Article 51 that countermeasures must be proportionate to the injury suffered. It is just that the drafters wanted to make it clear that in applying the principle of proportionality, the understanding of "injury" in the case of prohibited subsidies is not limited to the kinds of adverse effects that make actionable subsidies illegal. This makes sense when one considers that prohibited subsidies

3 These adverse effects are defined in the following terms in Article 5 of the SCM Agreement as one or more of: "(a) injury to the domestic industry of another Member [footnote omitted]; (b) nullification or impairment of benefits accruing directly or indirectly to other Members under GATT 1994 in particular the benefits of concessions bound under Article II of GATT 1994 [footnote omitted]; (c) serious prejudice to the interests of another Member [footnote omitted]." The concept of "serious prejudice," defined in detail in SCM Article 6, ceased to apply after 1999, however, because of its provisional nature, as set out in SCM Article 31. 
are export subsidies, whereas actionable subsidies are domestic subsidies; export subsidies may have adverse economic effects different and beyond those of domestic subsidies. In sum, "actionable" subsidies are themselves illegal and prohibited to the extent that they cause the adverse effects described in SCM Article 5; but because they are illegal only to the extent that they cause those particular adverse effects, an adjudicator must regard the adverse effects in question as an upper limit on countermeasures (SCM Article 7.8). Footnote 9 to Article 4.10 merely indicates that in the case of export subsidies, the proportionality of countermeasures must be assessed in light of the fact that these subsidies are "prohibited" per se, i.e. unlike "actionable" subsidies, prohibited regardless of whether the kind of adverse effects described in SCM Article 5 can be demonstrated by the complainant. But this hardly means that the injury to the defendant is irrelevant in assessing countermeasures in the case of "prohibited" subsidies; it is just that the adjudicator should not assume (as it is required to do in the case of actionable subsidies by SCM Article 7.8) that the injury is limited to the adverse effects described in Art. 5 in regard to "actionable" domestic subsidies.

\subsection{The analysis of the panel}

The arbitral panel in FSC misrepresented and misapplied this legal framework.

First of all, the panel took the reference to "prohibition" in Article 4.10, Footnote 9 not as a signal that the conception of economic injury for prohibited subsidies will be different from that for actionable subsidies, but rather as a basis for throwing out the window any effort to gauge the relationship of the subsidy to the injury suffered by the party requesting countermeasures.

The panel thus began its analysis of proportionality by reference to factors completely unrelated to the nature and extent of the injury suffered by the state requesting countermeasures. It noted that the US measure was "inherently destabilizing" or upsetting of the balance of legal rights and obligations. But defined in those abstract terms, so is any act in violation of a treaty norm; the whole basis of pacta sunt servanda is that violations of treaty norms undermine legal security, and the normative balance of rights and obligations. Such consequences therefore do not in themselves suggest a particular level of countermeasures, nor provide a basis for determining the gravity of a breach. 
Thus, the panel was forced to make a leap of logic between the concept of security and stability of the balance of legal rights and obligations to the notion that this particular subsidy, being widely available, "creates systematic uncertainty and instability of expectations as to trading conditions" (para. 6.9). But there is nothing in the SCM Agreement that entitles a WTO Member to certainty and stability of trading conditions. Instead, it has again and again been emphasized in WTO jurisprudence that, as a general matter (and with the qualified exception of non-violation nullification and impairment complaints), WTO rules do not entitle Members to fixed expectations of trading conditions, but only to legal certainty; the expectation that Members will continue to act in compliance with the specific constraints placed on their conduct in the treaties. (See US Section 301, Report of the Panel; EC - LAN Equipment, Report of the Appellate Body).

In considering the "gravity" of the breach the arbitral panel placed much weight on the fact that the export subsidies in question were "prohibited" per se under the SCM Agreement. But the categories of "prohibited" and "actionable" subsidies are merely terms of art in the SCM Agreement. The fact that the obligation with respect to the former category, export subsidies, is one of conduct whereas the obligation with respect to domestic subsidies is one of result (avoidance of certain adverse effects) does not in itself establish the special gravity of a violation of the SCM provisions on export subsidies. The panel here seems to be relying on a discredited notion in earlier versions of the draft ILC Articles that obligations of conduct are stricter than obligations of result; a view that, as Crawford explains, was explicitly rejected in the drafting of the final version of the Articles. (Crawford (2003), pp. 21-23; and see P.-M. Dupuy, "Reviewing the Difficulties of Codification: On Ago's Classification of Obligations of Means and Obligations of Result in Relation to State Responsibility").

The fact is that both prohibited and actionable subsidies attract state responsibility under the SCM Agreement.

In the case of actionable subsidies, there is a legal duty to "take appropriate steps to remove the adverse effects or... withdraw the subsidy" (7.8). As already noted, the failure to take such steps can result in countermeasures, which must be commensurate with "adverse effects" as defined in Articles 5 and 6 of the SCM Agreement. The only difference in the case of "prohibited" subsidies is that countermeasures are not limited by the concept of "adverse effects" in Articles 5 and 6. But it is a huge and unjustified leap to infer from this that "prohibited" subsidies are not 
subject to the general rules of international law on proportionality to the injury (admittedly a concept of injury that is not circumscribed by the particular meaning of "adverse effects" that is defined in the case of actionable subsidies in SCM 5 and 6).

It should be noted that most WTO obligations have been stated and interpreted as obligations of conduct or means, not result; and nevertheless, in respect of these hundreds or thousands of obligations of conduct, countermeasures are limited, under Article 22 of the DSU to measures of equivalent effect to the defendant Member's failure to implement. In sum, the general countermeasures regime of the WTO is inconsistent with the notion that the breach of an obligation of conduct has a special gravity to it, justifying countermeasures that may be in excess of the actual harm resulting from the failure to comply from a ruling.

This of course assumes that the panel was even correct in considering the gravity of the initial wrongful act, as opposed to the gravity of the failure to implement the panel ruling. Since under the WTO modification of the general international law of state responsibility and countermeasures, countermeasures are only available, as explained above, for the failure to comply with a binding dispute settlement ruling, it is arguable that the relevant wrongful act, the gravity of which must be considered, is this failure to comply, not the initial act of subsidization, though the two will have some relation, at least in certain cases.

Here it must be borne in mind that, as noted in the introductory section of this report, the United States attempted once to reform its FSC scheme to bring it into conformity with an initial Appellate Body ruling, but these changes were deemed inadequate by the 21.5 compliance panel, a finding upheld by the Appellate Body. When the revised scheme was found not to be adequate as an implementation measure, the United States engaged in serious negotiations with both domestic interests and the EC, to find a solution satisfactory to all parties. As far as the US behaviour goes after it was found not to be in compliance with its new scheme, there is nothing to suggest aggravation of the breach entailed in failing to implement. It should be noted that in any case the Appellate Body never characterized the US as acting in bad faith or pursuing an internationally wrongful purpose. Also, the FSC legislation is clearly a very complex piece of legislation that has economic implications that go beyond the context of trade, and relate to the entire corporate taxation approach of the US. This does not, of course, excuse the US for failing to implement the DSB ruling in a timely fashion; but it does suggest that 
there could be explanations for not doing so that do not suggest any particular element of "bad faith" or egregious violation in the US behaviour, as the panel sometimes suggests, for example, referring to the US as in "persistent violation" (paragraph 6.15).

Even if one sets aside these errors in applying the notion of gravity of breach, an analysis of the intrinsic gravity of the breaching act does not obviate the need to nevertheless consider, as well, the injury to the party requesting countermeasures. Thus, to revert to ILC Article 51, "Countermeasures must be commensurate with the injury suffered, taking into account the gravity of the internationally wrongful act and the rights in question (emphasis added)." This language cannot possibly justify the panel's conduct, which is to collapse the inquiry into injury, into an assessment of the gravity of the internationally wrongful act. If that were the intent, then Article 51 would refer only to commensurability with the internationally wrongful act; the reference to the injury suffered would be superfluous.

In any case, having ignored the basic notion of proportionality in international law, that of commensurability with the injury suffered, the panel invented its own conception of proportionality - how much it cost the breaching state to violate its international obligations! There is something odd in this reversal - the quantum of countermeasures being determined by the cost of the wrongful act to the perpetrator, not the cost to the victim. Of course, there is usually some relationship between the cost of a wrongful act to the perpetrator and the extent of harm to the victim state; the more that a state spends on chemical weapons, all things being equal, the greater the threat to other states. But the international law requirement of proportionality in countermeasures is not intended simply to establish some kind of arithmetic relationship - or ratio - between the wrongful act and the countermeasures, but rather to limit countermeasures so that they do not exceed the injury to the victim state. ${ }^{4}$ The arbitral panel was required by international law to address itself to

${ }^{4}$ Countermeasures can almost always be expressed as some proportion or ratio: so for example, in a dispute over wrongful treatment of aliens, the home state could demand countermeasures of $\$ 1,000,000$ for each alien improperly detained. There would be a "manifest relationship of proportionality" in the manner in which the panel understands proportionality, i.e. some kind of arithmetic ratio of countermeasures to the injury (the more aliens improperly treated the higher the quantum) but this would in no way answer the question of whether the countermeasures are disproportionate in the sense of excessive in relation to the injury taking into account the gravity of the breach, which is what is required by ILC Article 51 . 
whether, in using the amount of the entire subsidy it would be imposing an amount of countermeasures that exceeded the injury to the EC, properly understood. This the arbitral panel never did. By introducing other, mostly spurious or irrelevant meanings of proportionality, it simply avoided completely the question of the extent of injury to the state requesting countermeasures.

In turning to the costs of the subsidy as an appropriate benchmark for countermeasures, the arbitral panel sought to justify itself on the grounds that "financial contribution" was one of the elements of the internationally wrongful act in question, namely the continued provision of a prohibited export subsidy (para. 6.13). However, according to the SCM Agreement there is no element of wrongfulness whatsoever that attaches to the mere act of providing "financial contribution." Only where the financial contribution provides a "benefit" to a specific domestic firm or industry can any element of international wrongfulness attach to the act of subsidization. Thus no possibility of misfeasance arises by virtue of the "financial contribution" itself. The element of misfeasance is the conferral of a benefit on a domestic industry, through a subsidy contingent in law or in fact upon export performance. It is not as if some element or degree of wrongfulness arises from the "financial contribution" alone.

Thus, if the panel were to follow its own logic correctly it would relate the amount of countermeasures to the "benefit" - i.e. the competitive advantage over general market conditions conferred on domestic firms in consequence of the subsidy. Focusing on "benefit" would naturally lead to an analysis of the kind of economic harm to foreign firms competing with domestic US firms that was caused by the subsidy. And this in turn would have been much more consistent with, and indeed required, an inquiry into the nature and extent of the injury to the EC. At paragraph 6.21 of its ruling, the panel shows some dim awareness that "benefit" might be a more appropriate benchmark for assessing countermeasures than "financial contribution." The panel dismisses this concern by collapsing the notion of benefit into the notion of expense by the treasury, assuming benefit can be measured by the expended money that is granted to the firm. It is precisely such a move that was firmly rejected by the Appellate Body in Canada - Aircraft: “... we believe that Canada's argument that 'cost to government' is one way of conceiving of 'benefit' is at odds with the ordinary meaning of Article 1.1(b), which focuses on the recipient and not on the government providing the financial contribution." (para. 154; emphasis in original). 


\subsection{The prohibition of export subsidies as an "Erga Omnes" obligation}

The failure of the panel to consider properly whether countermeasures in the total amount of the financial contribution would be disproportionate to the injury suffered by the EC is particularly egregious when one considers that the financial cost of the subsidy extended to all firms doing business everywhere in the world, not just the EC. In fact, the United States was prepared to go along with the use of an amount based upon financial cost of the subsidy, provided that amount was prorated to reflect the EC's total percentage of total trade with the US. In other words, the US was prepared to accept an amount of countermeasures that equalled the amount of subsidization that could reasonably have been expected to have an effect on the EC's markets.

At this point, the reasoning of the panel seems, at best, convoluted. To begin with, the panel stated that it viewed the prohibition on export subsidies as an erga omnes obligation to the entire community, of a kind such that the level of countermeasures should take into account the harm to the community, and not simply the injury to the state requesting the countermeasures.

A prohibition on export subsidies cannot plausibly be an erga omnes obligation. Erga omnes obligations are considered to be largely co-extensive with ius cogens, peremptory norms of international law such as the prohibitions on torture and genocide. (Pauwellyn (2002)).

What the panel had in mind was, more likely, the concept of an erga omnes partes obligation, i.e. an obligation owed not only to each Member of the WTO individually, but to the entire Membership as a collectivity. As Pauwellyn notes, according to the Commentary on the ILC Articles, "[the]... principal purpose [of erga omnes partes obligations] will be to foster a common interest, over and above any interests of the States concerned individually."(Commentary, pp. 320-321, para (7)). Obligations in human rights and environmental treaties have been considered erga omnes partes: these obligations embody some universal principle or seek some global public good.

While, according to Pauwellyn, there are some elements of collective interest in WTO obligations, in most cases their principal purpose is to serve and protect the interests of individual Member states. The Preamble to the WTO Agreement states some common purposes or interests such as "allowing for the optimal use of the world's resources in accordance with the objective of sustainable development, ...", but makes it clear that the way in which the WTO contributes to such common interests is 
through "reciprocal and mutually advantageous arrangements directed to the substantial reduction of tariffs and other barriers to trade ..." (emphasis added). Thus, while they may serve some common interests and objectives, the nature of WTO obligations, generally speaking, is that they are "reciprocal and mutually advantageous."

Pauwellyn admits that there may be some obligations in the WTO Agreements (of an institutional framework nature) that could correctly be characterized as erga omnes partes; we do not necessarily agree with Pauwellyn's every characterization of a WTO obligation as bilateral. A full engagement with his position is beyond the scope of this Report. The panel, however, simply pulled out of a hat the notion that the prohibition on export subsidies is erga omnes partes. It failed to make any analysis whatever of the meaning of this concept (perhaps because it got the concept confused in the first place with erga omnes).

Is, then, the prohibition on export subsidies an erga omnes partes? Here, we return to the observation that export subsidization is only prohibited in the SCM agreement to the extent that it confers a "benefit"; in other words, such subsidization is only wrongful to the extent that it confers a competitive advantage beyond that which the entities in question would normally enjoy in the marketplace.

Why should conferring such a competitive advantage be internationally wrongful? This could only be so because of the effects on the economic interests of other states, i.e. the relative competitive positions of firms and industries in other WTO Member states. It is true that, in the case of export subsidies, unlike other subsidies, these effects are assumed once a benefit has been established, but such an assumption is reasonable where the subsidy is contingent on export. By knowing that a subsidy is a subsidy on exports, and that it confers a "benefit," i.e. a competitive advantage in respect of the exported products, we know that it is likely to affect competition in foreign markets. ${ }^{5}$ It is for this reason that proof of adverse effects on other WTO Members is not required to establish a violation. Contrary to what the arbitral panel apparently thinks, it is not that export subsidies are somehow wrongful regardless of their effects on

${ }^{5}$ By contrast domestic subsidies may be aimed at capturing positive externalities (public goods) within the domestic market, e.g. $\mathrm{R}$ and $\mathrm{D}$. They may be conferred on firms that do not trade internationally at all, or in areas of the economy where there is no significant import competition from other WTO Members. It is thus understandable that these domestic subsidies would only be wrongful, if shown to have the result of adverse affects on other WTO Members. 
trade of individual WTO Members. It is that, taken together, the facts that exports are targeted and that a benefit (competitive advantage) is conferred lead to Res Ipse Loquitur with respect to adverse affects on other WTO Members.

The conclusion with respect to prohibition on export subsidies is that this WTO obligation is principally aimed at protecting the economic interests of individual WTO Members, by preventing a Member from providing its own exports with an artificial competitive advantage in the markets of other WTO Members or third countries where that Member's exports are competing with those of other WTO Members.

But, to return to an issue raised earlier in this Report, the panel merely assumes that the obligation for violation of which countermeasures can be authorized under WTO law is the primary obligation, i.e. prohibition of export subsidies and not the secondary obligation to implement an adopted panel and/or Appellate Body ruling that the primary obligation has been violated.

Is this secondary obligation erga omnes partes? There is a community interest in the rule of law that is served by implementation of adopted reports and disserved by non-implementation; this is reflected in DSU 21.1, which states "Prompt compliance with recommendations or rulings of the DSB is essential in order to ensure effective resolution of disputes to the benefit of all Members." (emphasis added). On the other hand, DSU describes dispute settlement as aiming at a "prompt settlement of situations in which a Member considers that any benefits accruing to it directly or indirectly ... are being impaired by measures taken by another Member..." This language seems to make it clear that, while there is a community interest in compliance, the fundamental or primary interest at stake in dispute settlement is that of individual WTO Members in respect of measures taken by other Members. Thus, it is established in GATT/WTO practice that dispute settlement rulings are only legally binding between the parties, and not legally binding on the Membership as a whole, or the WTO as an organization (Japan - Alcohol).

Only a party to the initial proceedings may thus demand countermeasures; and this follows from the fact that the ruling that the defendant is failing to implement is binding on that Member only as a party to that proceeding, and not by virtue of being a Member of the WTO.

In sum, neither the primary nor the secondary obligation can reasonably be considered an obligation erga omnes partes.

In addition to the argument that the prohibition on export subsidies was an erga omnes (partes) obligation, the arbitral panel also justified its 
decision to not to adjust the total amount of countermeasures in light of the EC's percentage of global trade on the theory that the higher level of countermeasures would "have the practical effect of facilitating prompt compliance by the United States." However, as pointed out earlier in this analysis, proportionality as expressed in ILC Article 51 limits the level of countermeasures, even where a higher level might contribute to the legitimate objective of compliance.

Finally, disingenuously, the panel attacked the United States' argument that the amount of the countermeasures should be adjusted in light of the EC share of world trade on the grounds that this kind of method for calculating countermeasures would be "arbitrary." Why? "It simply presumes a one to one correspondence of dollar of subsidy to dollar of trade impact." (paragraph 6.9). But of course this is what the panel itself assumed in the first place in resorting to the total amount of the subsidy as the measure of injury (albeit to the entire Membership, on the erga omnes partes theory).

\subsection{Alternative approaches to quantum}

The Panel considered alternative approaches to calculating countermeasures, based on estimates of injury to the EC rather than the amount of subsidy; such approaches were in fact on the evidentiary record, presumably because the parties had some awareness that, in international law, proportionality cannot be evaluated without reference to injury to the victim state. The panel noted that at least on one approach to calculating the adverse effects on the EC, the amount could actually be higher than the total amount of the subsidy. It asserted that the United States had not been persuasive in showing that a better methodology would result in an amount of adverse effects on the EC below that of the total amount of the subsidy. Here the reasoning of the panel is as follows: the EC has proposed the entire amount of the financial contribution as the quantum of countermeasures; the United States has not proven that a clearly superior methodology for estimating the injury to the EC from the subsidy would result in a lesser amount; therefore, even if the amount of the subsidy is an arbitrary consideration in relation to injury, there is no compelling reason to reject the EC request. This seems to be an alternative basis for the panel's entire ruling, one that has nothing to do with the panel's earlier argument that the amount of the subsidy is directly related to the gravity of the breach and the injury, and that it 
is appropriate, because we are dealing with an erga omnes partes obligation, to base countermeasures on the injury to the entire WTO community.

While in fact this alternative theory of the ruling actually contradicts the prior analysis of the panel, it does at least have the advantage of being supported by precedent. In the Brazil - Aircraft case, the arbitral panel accepted the amount of the subsidy as the appropriate amount of countermeasures, observing that it was up to Brazil, the country challenging the amount of the countermeasures, to show that this amount was not "appropriate." The effect, according to the arbitral panel, was that in the case of the evidence being "in equipoise" Brazil would lose its claim of inappropriateness (Paras. 2.8-2.9).

Is this understanding of the burden of proof jurisprudentially sound? It is true that the effect of SCM 4.10-4.11 is that it will often be up to the state that is the target of countermeasures to challenge the quantum in arbitration; this is because 4.10 provides that the DSB shall directly authorize countermeasures, unless a Member seeks arbitration. Thus, where the DSB may be inclined to grant the countermeasures as requested by the Member that is victim of a breach, arbitration would only be likely to be invoked by the Member that is the target of the intended countermeasures to challenge the quantum. Thus, as a general matter it will be up to the party challenging the countermeasures to show that they are not "appropriate."

However, footnote 10 to 4.11 says that disproportionate countermeasures are not allowed; the arbitrator must not read the word "appropriate" in 4.11 to allow disproportionate countermeasures. This footnote, when considered in conjunction with the categorical requirement of proportionality in ILC Article 51, suggests that even if the party challenging the countermeasures has not as a general matter proven that they are inappropriate, the arbitrator must nevertheless insure that the countermeasures are not disproportionate. In other words, disproportionality is an exception to the general presumption that countermeasures proposed by the victim state are "appropriate" subject to the violator state showing otherwise. This would be consistent with the fact that, as Crawford puts it, "Article 51 establishes an essential limit on the taking of countermeasures"(p. 294). It is also consistent with the notion, suggested by Cannizzaro, that the principle of proportionality is aimed in some degree at curbing the traditional freedom of the victim state to assert countermeasures according to its own subjective standard (E. Cannizzaro (2002) p. 895). 


\section{Can countermeasures induce compliance?}

As discussed above, the arbitrators suggested that countermeasures should be considered as part of a property rule, i.e. as an incentive mechanism, and imply in their ruling that considerations of proportionality between the countermeasures and the injury suffered are secondary and subordinate to the overall goal of achieving compliance. This section discusses how compliance could be induced by countermeasures, and in particular countermeasures that could be applied by several countries. Here we assume that proportionality does not constrain the capacity of a state to take all countermeasures that might contribute to the goal of compliance. We conclude that in many circumstances, the application of countermeasures will lead to insufficient compliance; that is, member countries will optimally select countermeasures which do not induce the removal of the unlawful export subsidy. Even if several members apply countermeasures simultaneously, under-enforcement will occur in equilibrium. The concern that countermeasures should be scaled by the importance of trade between the country imposing the countermeasures and the country granting unlawful subsidies in order to avoid excessive countermeasures thus appears to be unfounded. At the opposite, under-enforcement (lack of compliance) will occur even when several countries impose countermeasures simultaneously without upper bound on the amount of countermeasures that they impose. However, under-enforcement will also take place in circumstances where it is efficient (from a welfare perspective), i.e. when export subsidies increase welfare. Paradoxically, letting the "victims" of export subsidies choose countermeasures will lead to unlawful but efficient subsidies. That is also to say however that the implementation of a property rule would allow for efficient breach.

The intuition for this is straightforward: export subsidies often bring benefits to the country granting them which are in excess of the cost that they impose on importing countries. ${ }^{6}$ To the extent that countermeasures take the form of export subsidies in another sector, ${ }^{7}$ they will have the same property and hence bring benefits to the country imposing them that are larger than the cost that they impose on the offending

${ }^{6}$ We are not claiming that this property holds with respect to the export subsidies that the FSC scheme involves.

${ }^{7}$ Alternatively, countermeasures may take the form of import tariffs in the same sector (see below). 
country. ${ }^{8}$ In those circumstances, the country imposing countermeasures will find it optimal to set countermeasures at the highest possible level which does not induce compliance. When several countries are involved, there will be a continuum of Nash equilibria, where importing countries (acting as multiple principals towards a common agent ${ }^{9}$ ) jointly impose the highest level of countermeasures that does not induce compliance.

The argument is developed formally in box 1 but it can be illustrated with a numerical example. Assume that country $\mathrm{C}$ grants an export subsidy, which brings a net benefit (additional profits less the subsidy) of 100. This subsidy imposes a cost to countries A and B, equal to 40 for each country (hence, 80 overall, so that costs are $80 \%$ of the benefit). As long as the importing countries impose countermeasures which, collectively brings them a benefit which is less than 125 (i.e. 100/0.8), and hence impose a cost on country $\mathrm{C}$ which is less than 100 (assuming that costs are again $80 \%$ of the benefit), country $\mathrm{C}$ will not comply. If they achieve this they will obtain (collectively) a surplus of 45 (i.e. 125-80) and the country that has imposed an unlawful subsidy will have no surplus left. Can the importing countries achieve this outcome non-cooperatively? Yes, as long as each importing country imposes countermeasures which bring a positive net surplus, each country will prefer not to impose countermeasures which would trigger compliance (taking the countermeasure of the other countries as given). Hence, any pair of countermeasures which brings a positive net surplus to each country will constitute mutual best replies.

So far we have assumed that countermeasures take the form of export subsidies in another sector. Whether this form of countermeasure is allowed is however not clear. In principle, countermeasures can take the form of the suspension of tariff concessions or "other obligations". What "other obligations" may include has not been clearly delineated by the case law and may not exclude the obligation not to introduce export subsidies (so that retaliation could take the form of export subsidies). In any event, the argument presented above would seem to extend to the case of the suspension of tariff concessions. Indeed, the introduction of export subsidies will shift the industry equilibrium in a way which is favorable to the exporting country and damaging to importers. If importers are allowed to introduce import tariffs, they will always be in a position to implement the initial equilibrium (before the introduction of the export

${ }^{8}$ Here again, we are not claiming that the EU can implement countermeasures which have this property in the context of the case at hand.

${ }^{9}$ See Bernheim and Whinston (1986). 
subsidies). This outcome will of course be preferable to them (they have the same consumer and producer surplus but gain some tariff revenues) so that they will fall short of inducing compliance. ${ }^{10}$

This reasoning has several implications. First, it suggests that complainants cannot be relied upon in order to induce compliance. When the incentive structure is such that the cost of an export subsidy is less than the benefit that it confers on the exporting countries, an arbitrator will have to grant countermeasures in excess of what the complainants seek in order to induce compliance. He will also face an issue of commitment as the complainants will have an incentive to implement a level of countermeasures short of what the arbitrators will decide. The arbitrators will have to monitor the imposition of countermeasures and compliance by the country imposing the unlawful export subsidy.

Second, the argument suggests that the implementation of a property rule does not necessarily imply large bargaining costs. The dispute settlement mechanism imposes a structure of move which yields an outcome in which the state wishing to deviate is left without surplus but in which breach takes place. Importantly, this outcome can take place even if the number of states that suffer from breach is large. These observations certainly suggest that the main drawback of a property rule, namely the importance of bargaining costs, may not be significant if bargaining is properly structured. By the same token, it suggests that a property rule may be superior to a liability rule.

Third, it appears that considering countermeasures in the context of a property rule would allow for efficient breach.

Finally, it appears that export subsidies and associated countermeasures can be used as a mechanism to induce multi-lateral export subsidies. Indeed, in the equilibrium that we describe, the country introducing the initial export subsidy is left without surplus while the complainants obtain (collectively and individually) a positive surplus. In equilibrium, all countries thus impose export subsidies. Consider now a repetition of "subsidy and countermeasure" stage game, where at each iteration one country imposes an export subsidy, which is subsequently subject to countermeasures falling short of inducing compliance. One expects to see the emergence of "collusive outcome" in such a repeated game where countries effectively introduce subsidies that yield no surplus in order to allow others to implement countermeasures which bring a positive surplus.

${ }^{10}$ We would like to thank Kyle Bagwell for pointing out this argument to us. 


\section{Box 1. A simple model of countermeasures}

We first illustrate that export subsidies can bring benefits in excess of the cost that they impose. Consider for instance a Cournot duopoly with homogenous goods, such that firms sell only in the domestic economy. Let $c_{1}$ and $c_{2}$ be the marginal cost of respectively foreign and domestic firms and let $s$ be the (unit) export subsidy granted to the foreign firm. Denote $\tilde{c}_{1}$ as the "effective" marginal cost of the foreign firm, i.e. its marginal cost less the unit subsidy. Welfare in the foreign country is given by profits less the subsidy and in the domestic economy it is given by the sum of the profit of the domestic firm and consumer surplus. Assume further that the marginal costs of the two firms are identical. Standard calculations confirm that in those circumstances, the fall in the domestic welfare following the imposition of a marginal subsidy (from zero) is less than the increase in foreign welfare. That is also to say that the export subsidy increases overall welfare. This arises because the export subsidy tends to correct the inefficiency associated with imperfect competition such that output is excessively low.

Consider now a game where at time $t_{1}$ country $\mathrm{C}$ can choose between a subsidy of zero and a subsidy of $\bar{s}$, which brings a net benefit $V(\bar{s})$. The cost incurred by two importing countries (A and B) are denoted respectively $c_{A}(\bar{s})$ and $c_{B}(\bar{s})$, with

$$
c_{A}(\bar{s})+c_{B}(\bar{s})<V(\bar{s})
$$

At time $t_{2}$, countries A and B can select countermeasures denoted $s_{A}$ and $s_{B}$, which bring respective benefits of $V\left(s_{A}\right)$ and $\mathrm{V}\left(s_{B}\right)$ and impose a cost on country $\mathrm{C}$ which is denoted $c\left(s_{A}\right)$ and $c\left(s_{B}\right)$, with $c\left(s_{A}\right)<V\left(s_{A}\right), c\left(s_{B}\right)<V\left(s_{B}\right)$.

At time $t_{3}$, country $\mathrm{C}$ can decide to remove the subsidy. If subsidies are removed, all countries get a payoff equal to zero. If the subsidies are not removed, each country incurs the cost and obtains the benefit associated with prevailing subsidies and countermeasures.

The decision of country $\mathrm{C}$ at time $t_{3}$ is straightforward. It will remove the subsidy as long as

$$
c\left(s_{A}\right)+c\left(s_{B}\right)>V(\bar{s})
$$

We adopt the (technical) assumption that if the cost of countermeasure is equal to the benefit of the initial subsidy, country $\mathrm{C}$ will prefer not to comply.

Consider now the decisions of countries A and B with respect to $s_{A}$ and $s_{B}$ at time $t_{2}$. We show that there is always an equilibrium $\left(\hat{s}_{A}, \hat{s}_{B}\right)$ such that neither $\mathrm{A}$, nor B induce compliance, i.e. such that $c\left(\hat{s}_{A}\right)+c\left(\hat{s}_{B}\right)<V(\bar{s})$ and such that

$$
V\left(\hat{s}_{A}\right)-c_{A}(\bar{s})>0, V\left(\hat{s}_{B}\right)-c_{B}(\bar{s})>0 .
$$


Assume that country B imposes a countermeasure $\overbrace{B}$ such that it prefers not to induce compliance, i.e. such that $V\left(\hat{s}_{B}\right)-c_{B}(\bar{s})=0$. We consider the best reply of country $A$, and show that it can obtain a positive payoff by not inducing compliance either. If it does not induce compliance, the best that country A can do is to choose a level of countermeasure such that (1.2) is met as a strict equality. Hence, using (1.1) and replacing $V(\bar{s})$ as an equality from (1.2), one obtains:

$$
c_{A}(\bar{s})+c_{B}(\bar{s})<c(\overbrace{A})+c(\overbrace{s_{B}})
$$

Using that $V\left(\hat{s}_{B}\right)=c_{B}(\bar{s})$, and, $c\left(\widehat{s}_{A}\right)<V\left(\overparen{s}_{A}\right)$ one obtains that:

$$
c_{A}(\bar{s})+V\left(\hat{s}_{B}\right)<V(\overbrace{A})+c(\overbrace{s_{B}})
$$

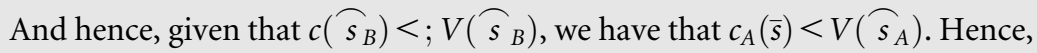
country A will be better off not to induce compliance. Finally, note that if A does not induce compliance, it is indeed also a best reply for B not to induce compliance (i.e. to implement $\widehat{s}_{B}$ ). Hence, there is a Nash equilibrium in which neither A nor B induce compliance. One can also further describe the set of equilibrium countermeasures that do not induce compliance. Denote $S_{B}$ as the optimal countermeasure imposed by B when country A imposes a countermeasure such that $V\left(\breve{s}_{\mathrm{A}}\right)=c_{A}(\bar{s})$, i.e. such that it has no surplus. $\left(\breve{s}_{\mathrm{A}}, \breve{s}_{\mathrm{B}}\right)$ is also a Nash equilibrium. For any $s_{A} \in\left[\breve{s}_{A}, \widehat{s}_{A}\right]$, there will be some $s_{B} \in[\overbrace{s_{B}}, \breve{s}_{B}]$, such that equilibrium conditions $((1.2)$ and (1.3)) hold. This follows simply by continuity of the equilibrium conditions. The shape of the frontier will be depend on the shape of $V($.$) and C($.$) .$

Let us finally consider the decision of country $\mathrm{C}$ at time $t_{1}$. In equilibrium, it will obtain no surplus. We make the assumption that it prefers to introduce an export subsidy for instance because it obtains some transitory benefits in between $t_{1}$ and $t_{2}$.

\section{Conclusion}

Overall, this chapter has argued that a property rule approach to countermeasures does not sit comfortably with established principles of international law. The chapter has however also highlighted the attraction of such an approach, to the extent that it would allow for efficient breach even in the presence of a large number of parties.

The implementation of a property rule approach to countermeasures may still be difficult in practice. The distribution of rents between victims may for instance raise some difficult issues. As argued above, victims may 
be able to achieve an equilibrium where the countermeasures that they claim do not induce compliance. There are however many such equilibria which correspond to different distributions of countermeasures. This may very well lead to a race to the courthouse. To protect their interest in eventually being awarded countermeasures, WTO Members will want to sue now, lest some other Member get there first, and receive all the countermeasures.

\section{References}

Bernheim, D. and M. Whinston, (1986), Common Agency, Econometrica, 54 (4), 923-942.

Bond, E., (1996), Competition Policy in Customs Unions: a Natural Experiment using State Level Antitrust Enforcement, mimeo, Pen State.

Cannizzaro, E., (2001), The Role of Proportionality in the Law of International Countermeasures, European Journal of International Law, 12.

Crawford, J., (2002), The International Law Commission's Articles on State Responsibility: Introduction, Text, and Commentaries, Cambridge: Cambridge University Press.

Mavroidis, P., (2000), Remedies in the WTO Legal System: between a Rock and a Hard Place, European Journal of International Law, 11 (4), 763-813.

Pauwellyn, J., (2002), "The Nature of WTO Obligations", Jean Monnet Working Paper, at www.jeanmonnetprogram.org, p. 8.

Schwartz, W. and A. Sykes, (2002), The Economic Structure of Renegotiation and Dispute Resolution in the World Trade Organisation, The Journal of Legal Studies, $31 \mathrm{~J}$. 